Journal of Advanced Research in Fluid Mechanics and Thermal Sciences

\title{
Electro-Thermal Modeling of Power IGBT Module Cooled by A Heat Pipe Cooling System
}

\author{
Améni Driss ${ }^{1}$, Samah Maalej ${ }^{1}$, Mohamed Chaker Zaghdoudi ${ }^{1, *}$ \\ 1 Laboratoire Matériaux, Mesures et Applications (MMA), Institut National des Sciences Appliquées et de Technologie (INSAT), University of \\ Carthage, Centre Urbain Nord, BP N $676-1080$ Tunis Cédex, Tunisia
}

\section{ARTICLE INFO}

\section{Article history:}

Received 7 November 2020

Received in revised form 25 May 2021

Accepted 10 June 2021

Available online 14 August 2021

\section{Keywords:}

Electronics cooling; heat pipes; IGBT; electro-thermal modeling

\section{ABSTRACT}

This paper deals with the development of an electro-thermal model of an Insulated Gate Bipolar Transistor (IGBT) with a water-cooled heat pipe cooling system. Firstly, a thermal model of the heat pipe cooling system is proposed. Then, an electro-thermal model of the IGBT is developed to predict the junction temperature variations in transient operation. The thermal model of the IGBT is determined on the base of the thermal-capacitance lumped method. The electrical model of the IGBT is developed by considering the effect of the junction temperature on its static electrical parameters. Finally, the electro-thermal model is considered in a boost converter application. The model predictions show the effectiveness of the heat pipe cooling system for different commutation frequencies. It is proved that the heat pipe cooling system can keep the junction temperature of the IGBT at values allowing safe operation.

\section{Introduction}

The Insulated Gate Bipolar Transistors (IGBT) are widespread electronic components that can be found in numerous power conversion systems and motor drive applications. These devices that operate with high switching frequencies and high current and voltage levels become more compact. As a result, they generate high heat power densities that cause a junction temperature increase. The thermal management of the IGBT modules is one of the major problems in the power electronics industry since it affects the reliability, lifetime, and safety of the electrical systems. Conventional techniques such as air or liquid cooling systems are unable to remove high power densities. Hence, an alternative solution is to operate with phase change cooling systems such as heat pipes which are used in various thermal applications such as electronics cooling, evaporative cooler, solar thermal energy technologies, etc. [1-3]. Heat pipes are widespread techniques that are used to cool IGBT modules. Figure 1(a) shows an air-cooled heat pipe system, which is composed of an aluminum block on which the IGBT power modules are fixed, a set of heat pipes, and fins. Electrical insulation can be considered between the heating and the cooling areas for applications where the power modules operate with high voltages so that electrical breakdown can be avoided. Although these air-cooled

\footnotetext{
* Corresponding author.

E-mail address: chaker.zaghdoudi@insat.rnu.tn
}

https://doi.org/10.37934/arfmts.86.1.105122 
heat pipe systems demonstrate good thermal efficiency; however, some limitations appear due to the use of fans. Hence, other effective solutions are explored, and they consider water-cooled heat pipe systems (Figure 1(b)). These cooling techniques can be as efficient as the air-cooled heat pipe ones, and even better if we consider the fact that, due to its specific heat capacity, water can transfer heat powers greater than those transferred by air.

The proper operation of the IGBT is insured when the junction temperature, $T_{j}$, is maintained within an optimum range that assures a safe operation [4]. The junction temperature must be lower than $90{ }^{\circ} \mathrm{C}$ for standard electronic applications and $125{ }^{\circ} \mathrm{C}$ for special ones such as military applications. In steady-state operation, the overall thermal resistance of the thermal chain (IGBT and cooling system) should be lower than the temperature difference between the junction and the heat sink temperature divided by the heat power dissipated by the IGBT. This overall thermal resistance includes a thermal resistance between the junction and the electronic component case, which is generally given by the manufacturer, and the thermal resistance of the cooling system that is fixed between the case and heat sink. This latter thermal resistance should be calculated to comply with the previously mentioned condition. Hence, the design of the cooling system is generally based on the steady-state operation of the electronic component. This can fix the order of magnitude of the thermal resistance of the cooling system, but it is not enough. Hence, the thermal design should consider the electronic component operation in a transient regime. This supposes to consider a thermal tool that includes the thermal design of the IGBT and the cooling system. Knowing that the electrical parameters of the IGBT depend on the junction temperature, an electro-thermal model should be considered.

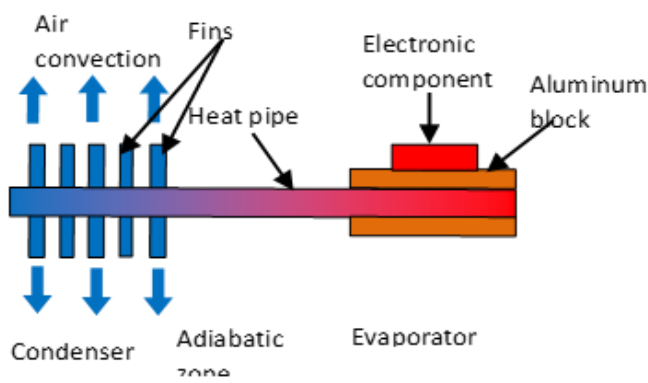

(a)

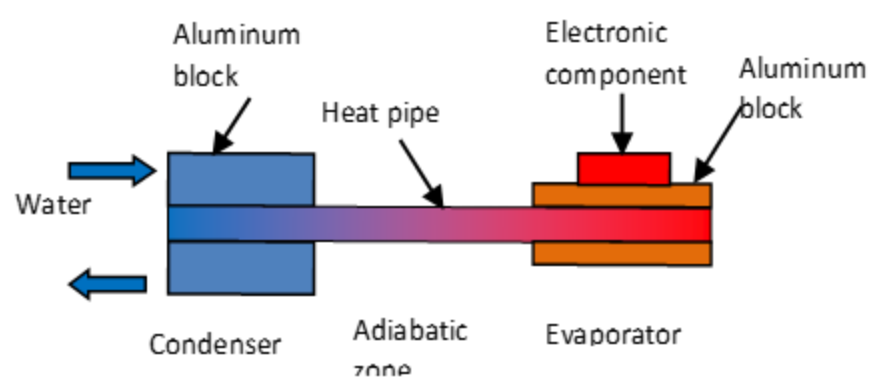

(b)

Fig. 1. Cooling system for IGBT modules combining (a) heat pipes and forced air convection, and (b) heat pipes and water cooling

Several researches focused on measuring or predicting the junction temperature using various methods among them we can distinguish the direct and indirect measurements as well as the thermal models [5-7]. In the literature, there are various numerical methods for the thermal analysis of the electronic components among them we can distinguish the finite element method (FEM), and the finite difference method (FDM) [8]. Another approach consists of modeling the IGBT by a set of RC cells [9-16].

As the heat power dissipation of the IGBT is a key parameter for the thermal study, it should be calculated using an electrical model. Several electrical models are presented in the literature [10,17$22]$. There are those based on the concept of the equivalent circuit $[10,19,20]$, and those based on the analysis of the different material layers that compose the IGBT structure $[18,23]$. Almost all the published works focused on the electro-thermal modeling of the IGBT without considering its cooling system. However, the electro-thermal behavior of the IGBT depends greatly on the cooling system, which must be considered in the modeling of the overall system. 
In previous work, a prototype of a heat pipe cooling system was developed and tested for different operating conditions such as the heat sink temperature and the heat input power [24]. A lumped thermal model is proposed based on RC thermal network. The comparison between the experimental and the simulated results showed a good agreement. This paper aims to predict the junction temperature of an IGBT module with a heat pipe-based cooling system to assess its design suitability. The originality of this work lies in the approach adopted for the electro-thermal modeling of the IGBT but also in the modeling of the cooling solution, which is based on a water-cooled heat pipe system. Firstly, the thermal modeling of the heat pipe cooling system is considered based on a lumped RC network circuit. Secondly, a thermal model for the IGBT is developed based on its transient thermal impedance response. Thirdly, an electrical model of the IGBT, which considers the variations of the static electrical sensitive parameters as a function of the junction temperature, is implemented. Finally, a complete electro-thermal model of the IGBT module with its cooling system is considered for a boost converter application.

\section{Thermal Modeling of the Heat Pipe Cooling System}

The heat pipe cooling system is shown in Figure 2. It is composed of a heat pipe and two cubic aluminum blocks (side $=60 \mathrm{~mm}$ ). The heat pipe, which is filled with water (fill charge $=6 \mathrm{cc}$ ), is cylindrical and it is made of copper (thermal conductivity $=380 \mathrm{~W} / \mathrm{m} . \mathrm{K}$ ). Its overall length is $190 \mathrm{~mm}$, and the evaporator, adiabatic section, and condenser lengths are $60 \mathrm{~mm}, 70 \mathrm{~mm}$, and $60 \mathrm{~mm}$, respectively. The capillary structure is composed of 75 helicoidal and trapezoidal grooves (Figure 3 ). The geometrical characteristics of the grooves are listed in Table 1.

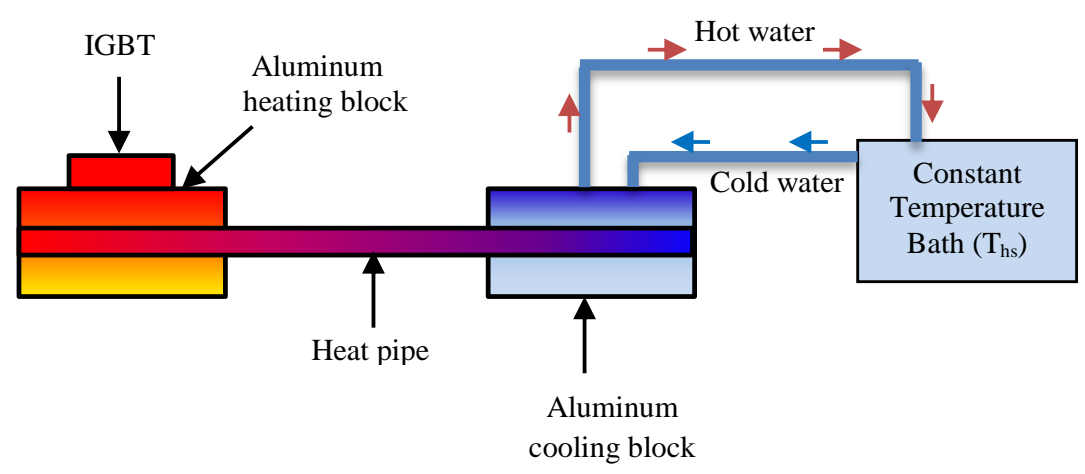

Fig. 2. Schematic of the heat pipe cooling system
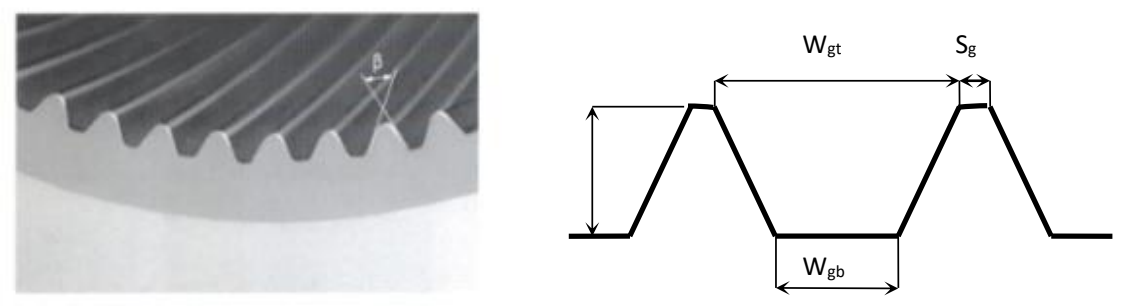

Fig. 3. Schematic of the grooves 
Table 1

Geometrical characteristics of the heat pipe

\begin{tabular}{ll}
\hline Outer Diameter, $D_{\text {out }}$ & $15.87 \mathrm{~mm}$ \\
Wall thickness, $\mathrm{t}_{\mathrm{w}}$ & $0.58 \mathrm{~mm}$ \\
Groove depth, $\mathrm{D}_{\mathrm{g}}$ & $0.3 \mathrm{~mm}$ \\
Groove width at the bottom, $\mathrm{W}_{\mathrm{gb}}$ & $0.266 \mathrm{~mm}$ \\
Groove width at the top, $\mathrm{W}_{\mathrm{gt}}$ & $0.599 \mathrm{~mm}$ \\
Apex angle the groove top, $\beta$ (Figure 3) & $29^{\circ}$ \\
\hline
\end{tabular}

The IGBT module is attached to an aluminum-heating block as in the actual application. Thus, the heat is transferred first by thermal conduction through the heat source block and then, it is transported through the heat pipe to the heat sink block, which is cooled by a refrigerated circulation bath. This arrangement enables to place the high-power electronic component far away from the cold plates so that problems due to water leaks and electric breakdown can be avoided if high voltages are used.

In previous works [24,25], experiments were carried out to thermally characterize the operation of the heat pipe cooling system in transient and steady-state regimes. The experimental bench includes the water-cooled heat pipe system including two aluminum blocks (heating and cooling blocks) and a heat pipe (Figure 4). The temperature distribution along the heat pipe is determined by ten thermocouples which are calibrated with an accuracy of $0.5^{\circ} \mathrm{C}$ and the measurements are recorded by an HP34970 data acquisition system (Figure 5). Hence, three thermocouples are considered in the evaporator section, four thermocouples are inserted in the adiabatic zone, and three thermocouples are located in the condenser section. From these measurements, the cooling system is modeled by using the thermal-electrical analogy as is shown in Figure 6 . Hence, five sections are identified and represented by RC networks, namely: the heating block, the evaporator, the adiabatic zone, the condenser, and the cooling block. The heat input power is modeled as a power generator and the heat sink is a voltage source. Five temperatures are considered in the lumped model: the temperature of the heating block, $T_{a l}$, the evaporator temperature, $T_{e v}$, the temperatures at the inlet and outlet of the adiabatic section, $T_{s e}$ and $T_{s c}$, and the condenser temperature, $T_{c}$. The evaporator and the condenser temperatures are determined experimentally by considering the average of the temperatures measured in these areas. The thermal resistances are determined from steady-state tests of the heat pipe cooling system [25]. The thermal capacitances are determined theoretically based on the technological aspects of the heat pipe and depend on the liquid distribution in the evaporator and condenser sections as well as the porosity of the capillary structure [25]. The values of the thermal resistances depend on the heat input power and the operating watercooling temperature, Ths. However, the thermal capacitances are hardly affected by these parameters. In this study, we have considered the values listed in Table 2 for different heat input powers and a heat sink temperature of $35^{\circ} \mathrm{C}$ for the horizontal position of the heat pipe. The choice of these values is motivated by the order of the magnitude of the heat power dissipated by the IGBT as it will be shown in section 4. The designed heat power of the heat pipe cooling system is higher than that dissipated by the IGBT. Figure 7 reports the variations of the heat pipe thermal resistance as a function of the heat input power for different water-cooling temperatures. Firstly, the thermal resistance decreases as the heat input power increases until the capillary limit, which represents the maximum heat transport transferred by the heat pipe for which the driving capillary pressure cannot overcome anymore the liquid, vapor, and hydrostatic pressure drops. Hence, for heat input powers that are lower than the capillary limit, the condensate flows back to the evaporator through the capillary structure, and the evaporator is well supplied with liquid, which improves the heat transfer between the evaporator wall and the liquid. For heat input powers higher than the capillary limit, the 
evaporator is not supplied correctly with the condensate, and it starts to dry. Consequently, the evaporation process is altered, and the heat transfer is degraded. As can be seen from Figure 7, the capillary limit depends on the water-cooling temperature. It increases from $105 \mathrm{~W}$ to $125 \mathrm{~W}$ when the water temperature cooling increases from $\mathrm{T}_{\mathrm{hs}}=10^{\circ} \mathrm{C}$ to $\mathrm{T}_{\mathrm{hs}}=45^{\circ} \mathrm{C}$. As it will be demonstrated in section 4 , these maximum heat transport capacities are higher than those dissipated by the IGBT.

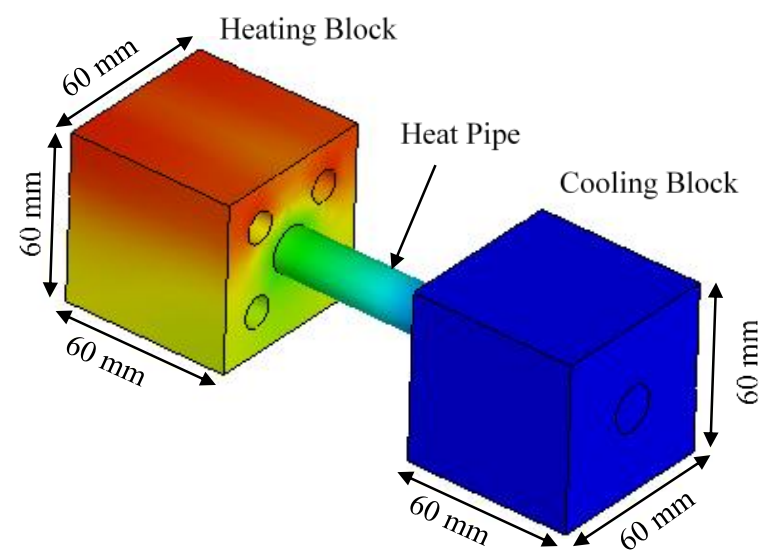

Fig. 4. Designed cooling system

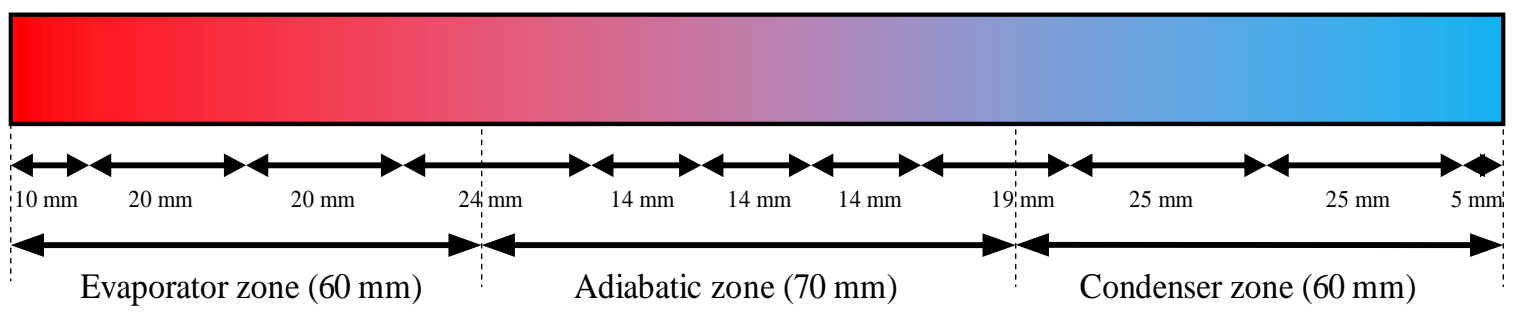

Fig. 5. Thermocouple locations

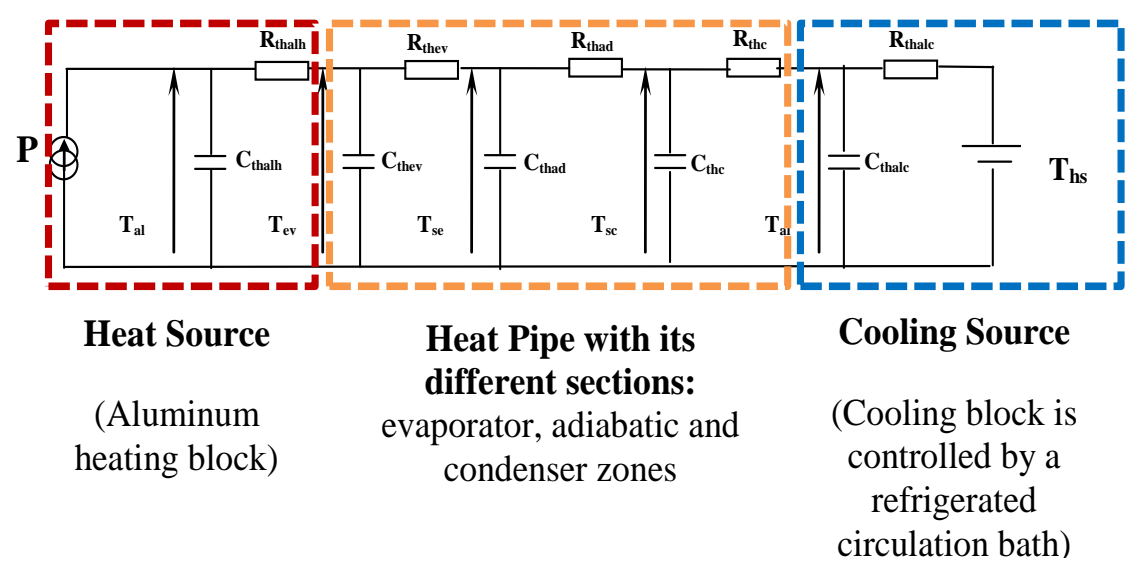

Fig. 6. RC lumped circuit for the heat pipe cooling system 


\section{Table 2}

Values of the thermal resistances and capacitances of the lumped RC thermal model of the heat pipe for different heat input powers $\left(\mathrm{T}_{\mathrm{hs}}=35^{\circ} \mathrm{C}\right)$

\begin{tabular}{llll}
\hline $\mathrm{Q}(\mathrm{W})$ & 100 & 80 & 60 \\
\hline$R_{\text {thalh }}(\mathrm{K} / \mathrm{W})$ & 0.081 & 0.081 & 0.081 \\
$\mathrm{R}_{\text {thev }}(\mathrm{K} / \mathrm{W})$ & 0.063 & 0.053 & 0.055 \\
$\mathrm{R}_{\text {thad }}(\mathrm{K} / \mathrm{W})$ & 0.007 & 0.007 & 0.007 \\
$\mathrm{R}_{\text {thc }}(\mathrm{K} / \mathrm{W})$ & 0.081 & 0.088 & 0.097 \\
$\mathrm{R}_{\text {thalc }}(\mathrm{K} / \mathrm{W})$ & 0.060 & 0.060 & 0.060 \\
$\mathrm{C}_{\text {thalh }}(\mathrm{J} / \mathrm{K})$ & 526.2 & 526.2 & 526.2 \\
$\mathrm{C}_{\text {thev }}(\mathrm{J} / \mathrm{K})$ & 9.3 & 9.3 & 9.3 \\
$\mathrm{C}_{\text {thad }}(\mathrm{J} / \mathrm{K})$ & 85.5 & 85.5 & 85.5 \\
$\mathrm{C}_{\text {thc }}(\mathrm{J} / \mathrm{K})$ & 9.26 & 9.26 & 9.26 \\
$\mathrm{C}_{\text {thalc }}(\mathrm{J} / \mathrm{K})$ & 526.2 & 526.2 & 526.2 \\
\hline
\end{tabular}

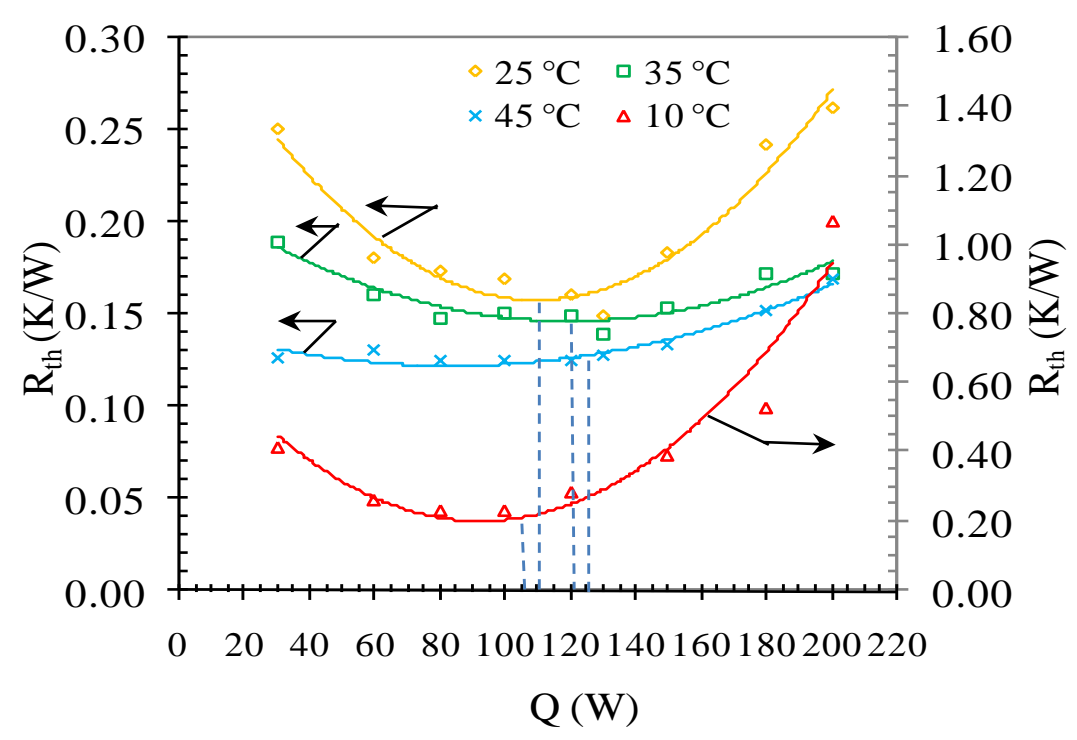

Fig. 7. Variations of the heat pipe thermal resistance versus the heat input power $\left(\mathrm{T}_{\mathrm{hs}}=35^{\circ} \mathrm{C}\right)$

Figure 8 illustrates the variations of the temperatures that are measured (continuous lines) and those calculated according to the model of Figure 6 (dashed lines) for a heat input power of $Q=80$ $\mathrm{W}$ and a heat sink temperature of $\mathrm{T}_{\mathrm{hs}}=35^{\circ} \mathrm{C}$. The calculated and the experimental results for the evaporator and the condenser temperatures show a good agreement whatever the heat sink temperature in the steady-state regime [24]. 


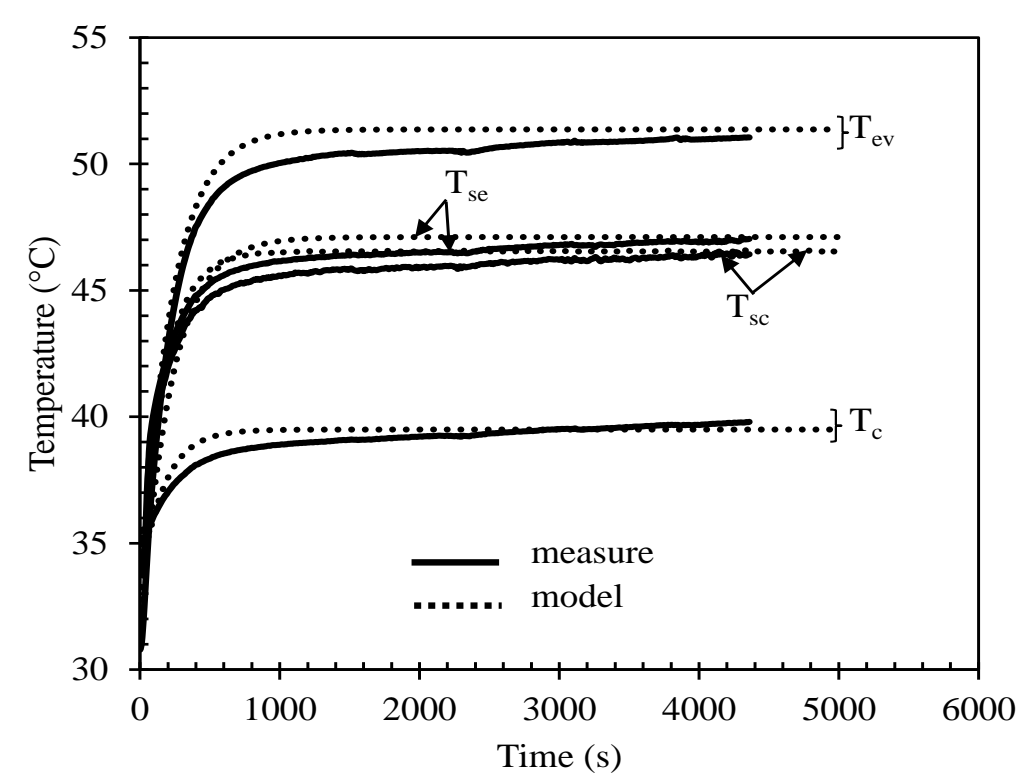

Fig. 8. Comparison between the measured and the calculated temperatures for $\mathrm{Q}=80 \mathrm{~W}\left(\mathrm{~T}_{\mathrm{hs}}=35^{\circ} \mathrm{C}\right)$

\section{Electro-Thermal Modeling of the IGBT}

\subsection{Thermal Modeling of the IGBT}

In this study, we consider an IGBT module, which is manufactured by Semikron and referenced as SKM 75GB 123D [26]. The transient thermal impedance curves for the diode and the IGBT, which are provided by the manufacturer, are given in Figure 9. In this study, we have focused on the thermal performance of the IGBT and we have not considered the thermal effects of the diode in the model.

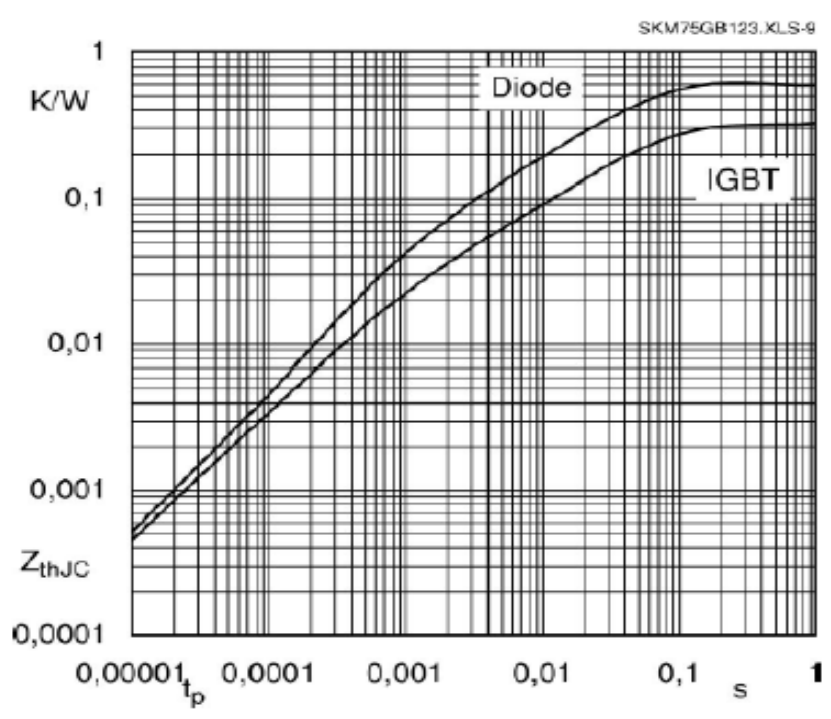

Fig. 9. Transient thermal impedance from junction to case of the IGBT [26]

The thermal impedance curve, which is based on the Foster RC network (Figure 10(a)), can be expressed by

$Z_{j c}(t)=\sum_{i=1}^{4} R_{i}\left(1-\exp \left(-t / \tau_{i}\right)\right)$ 
where $\tau_{i}=R_{i} C_{i}$ is the thermal time constant.

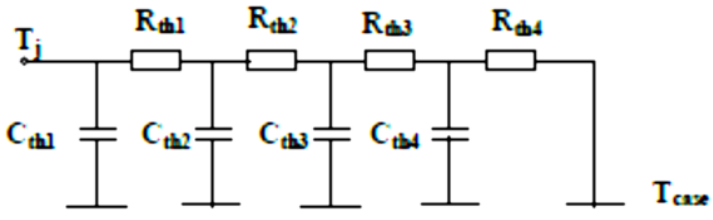

(a)

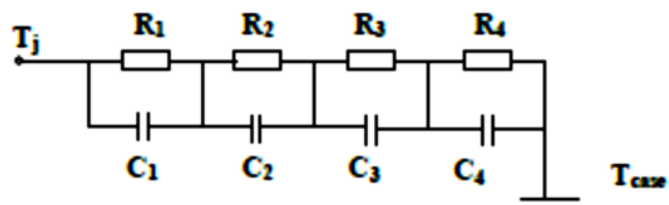

(b)

Fig. 10. Thermal RC network for IGBT: (a) Cauer model, and (b) Foster model

The thermal parameters that are extracted from the transient thermal impedance curve of the IGBT are listed in Table 3. The transfer function of the thermal RC network is obtained by applying the Laplace transform to Eq. (1) according to

$Z_{j c}(s)=\sum_{i=1}^{4} \frac{R_{i} / \tau_{i}}{s+1 / \tau_{i}}$

Table 3

Thermal parameters extracted from the transient thermal impedance curve for the IGBT module (Foster model)

\begin{tabular}{lllll}
\hline $\mathrm{i}$ & 1 & 2 & 3 & 4 \\
\hline $\mathrm{R}_{\mathrm{i}}(\mathrm{K} / \mathrm{W})$ & 0.180 & 0.064 & 0.022 & 0.004 \\
国 $_{\mathrm{i}}(\mathrm{s})$ & 0.0327 & 0.0479 & 0.008 & 0.005 \\
\hline
\end{tabular}

The mathematical transformation presented in $[12,27,28]$, is used to obtain the RC parameters of the Cauer model as shown in Figure 10(b). The transformation method is based on a continuedfraction expansion. Hence, Eq. (2) needs to be presented by the following expression

$$
Z_{j c}(s)=\frac{1}{s C_{t h 1}+\frac{1}{R_{t h 1}+\frac{1}{s C_{t h 2}+\frac{1}{R_{t h 2}+\frac{1}{s C_{t h 3}+\frac{1}{R_{t h 3}+\frac{1}{s C_{t h 4}+\frac{1}{R_{t h 4}}}}}}}}}
$$

This mathematical transformation is carried out in a program written in Mupad/MATLAB. The transformed parameters of the Cauer model are listed in Table 4. The thermal RC network describing the thermal behavior of the IGBT module between the junction and the case is illustrated in Figure 11.

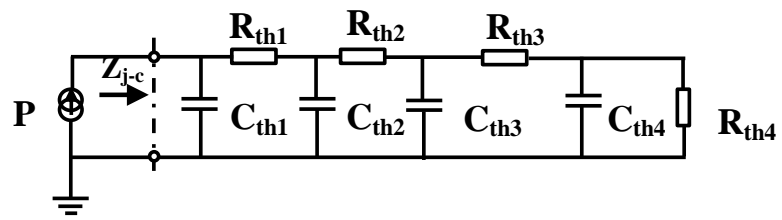

Fig. 11. Thermal model of the IGBT module 


\section{Table 4}

Parameters of the thermal model of the IGBT module from junction to case (Cauer model)

\begin{tabular}{llll}
\hline$R_{\text {th1 }}(\mathrm{mK} / \mathrm{W})$ & 0.1542 & $\mathrm{C}_{\text {th1 }}(\mathrm{J} / \mathrm{K})$ & 0.0962 \\
$R_{\text {th2 }}(\mathrm{mK} / \mathrm{W})$ & 0.0940 & $\mathrm{C}_{\text {th2 }}(\mathrm{J} / \mathrm{K})$ & 0.1352 \\
$R_{\text {th3 }}(\mathrm{mK} / \mathrm{W})$ & 0.0188 & $\mathrm{C}_{\text {th3 }}(\mathrm{J} / \mathrm{K})$ & 0.4094 \\
$R_{\text {th4 }}(\mathrm{mK} / \mathrm{W})$ & 0.0029 & $\mathrm{C}_{\text {th4 }}(\mathrm{J} / \mathrm{K})$ & 14.7793 \\
\hline
\end{tabular}

\subsection{Electrical Modeling of the IGBT}

The electrical model of the IGBT is a compact-type one, which is implemented in the SimPowerSystems library of MATLAB. Nevertheless, this model does not consider the effect of the junction temperature on the electrical parameters. Hence, a software module is developed, and some modifications are introduced to the expressions of the on-state resistance, $R_{0}$, and the threshold voltage, $\mathrm{V}_{0}$, of the IGBT according to

$\mathrm{V}_{0}=\mathrm{V}_{00}+\mathrm{a} \mathrm{T}_{\mathrm{j}}$

$R_{0}=R_{00}+b T_{j}$

$V_{00}$ is the voltage threshold at $0{ }^{\circ} \mathrm{C}$, and $R_{00}$ is the electric resistance at $0{ }^{\circ} \mathrm{C}$. a and $\mathrm{b}$ are sensitivity coefficients to the temperature, and $T_{j}$ is the junction temperature. The variations of the tension $V_{0}$ and the resistance $R_{0}$ as a function of the junction temperature are obtained experimentally [29], and it is found that $\mathrm{V}_{00}=0.5 \mathrm{~V}, \mathrm{a}=3 \times 10^{-3} \mathrm{~V} /{ }^{\circ} \mathrm{C}, \mathrm{R}_{00}=9 \times 10^{-2} \Omega$ and $\mathrm{b}=3 \times 10^{-4} \Omega /{ }^{\circ} \mathrm{C}$. Hence, the voltage drop, $V_{c e}$, between the collector and the emitter in the linear zone can be expressed as

$V_{c e}=V_{0}+R_{0} I_{c}$

$I_{c}$ is the collector current.

Figure 12 shows the modified electrical model of the IGBT. The block diagram of the IGBT model is composed of the three standard terminals (gate, emitter, and collector), and a fourth one, which corresponds to the junction temperature, is added. The electrical model can calculate the instantaneous electrical power according to the following equation

$P(t)=V_{c e}(t) I_{c}(t)$

$\mathrm{V}_{c e}$ is the collector-emitter voltage. 
Electrical model of implemented in

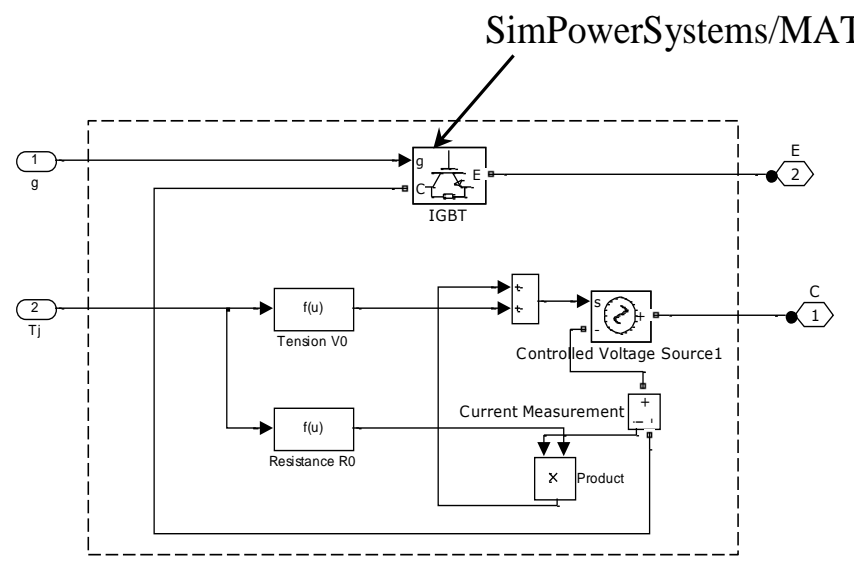

Fig. 12. The electrical model of the IGBT module implemented in MATLAB and including the temperature-sensitive parameters

\subsection{Electro-Thermal Modeling of the IGBT With the Cooling System}

To simulate the results, a boost converter application is considered. The circuit parameters of the boost converter are listed in Table 5. The IGBT is cooled by the heat pipe system as is shown in Figure 2. The IGBT and the heat pipe cooling system are modeled by considering RC thermal network using the thermal-electrical analogy that is analyzed and developed in sections 2 and 3 (Figure 13). In this model, we suppose a perfect thermal contact between the IGBT and the heat pipe. If a thermal interface material is included between the IGBT module and the heat pipe, an RC thermal network should be considered in the circuit to consider the heat transfer within this thermal interface material.

Table 5

Circuit parameters of the boost converter

\begin{tabular}{lll}
\hline Description & Symbol & Value \\
\hline DC source & $\mathrm{E}$ & $25 \mathrm{~V}$ \\
Inductance & $\mathrm{L}$ & $500 \mu \mathrm{H}$ \\
Capacitance & $\mathrm{C}$ & $25 \mu \mathrm{F}$ \\
Resistance & $\mathrm{R}$ & $50 \Omega$ \\
\hline
\end{tabular}

Figure 13 shows the block diagram of the model, which is implemented in SimPowerSystems/MATLAB. It is composed of two main block diagrams. The first one, at the top of Figure 13, corresponds to the boost converter model, and the second one, at the bottom of Figure 13 , corresponds to the electro-thermal model of the IGBT with its cooling system. The parameters of the RC thermal network of the IGBT and the heat pipe cooling system are those listed in Tables 2 and 4. The values of Table 2 are chosen since they correspond to the instantaneous heat power dissipated by the IGBT in the boost converter application as it will be demonstrated in Figure 14-16. The instantaneous power that is dissipated by the IGBT can be higher than the values that are chosen in Table 2, especially in the initial stage of the boost converter start-up. However, the duration of this stage is very short when compared to the thermal response time of the overall thermal system. Hence, the very high dissipation in the start-up regime affects hardly the thermal response of the IGBT as well as that of its cooling system. 


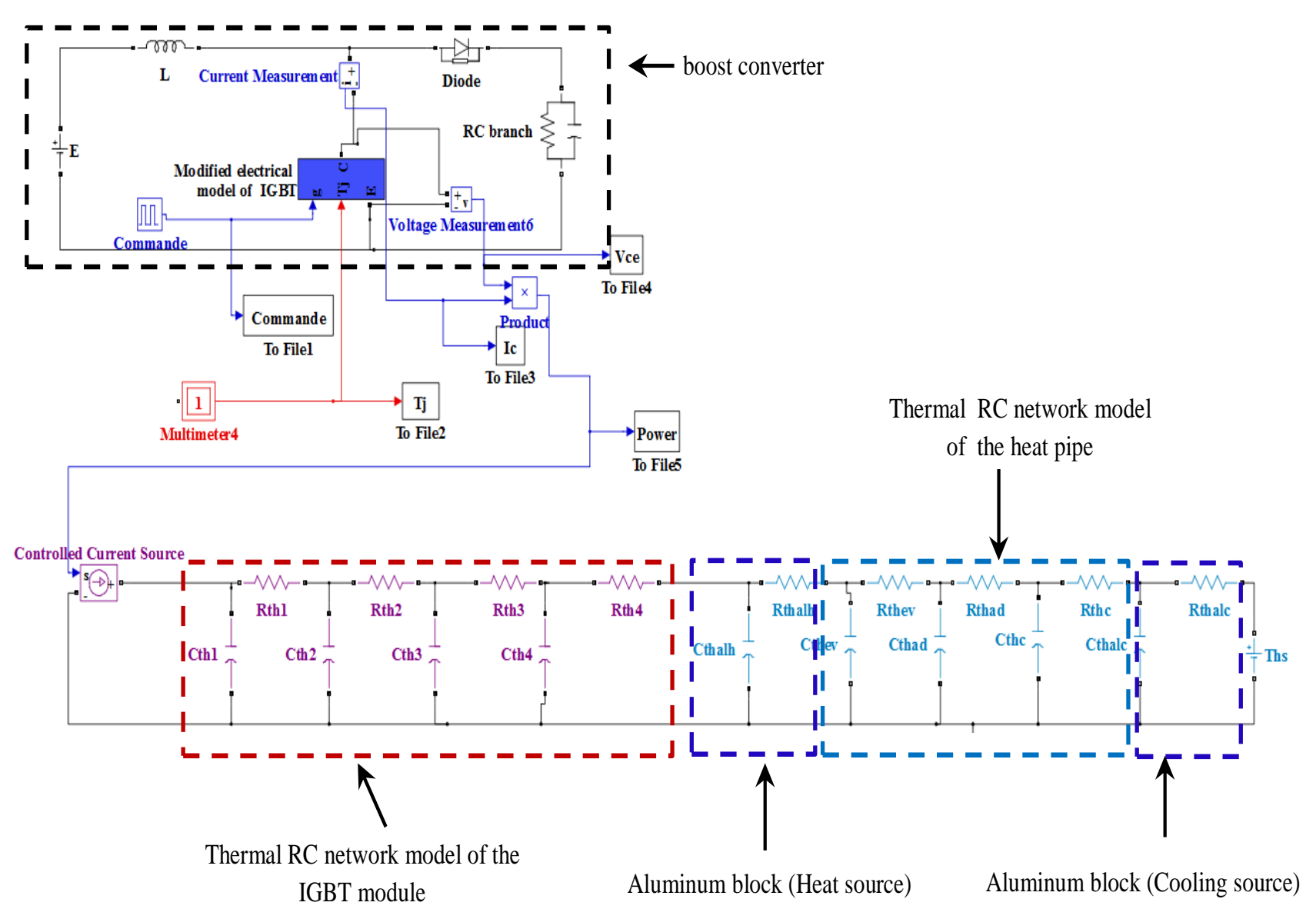

Fig. 13. Electro-thermal model of the IGBT module with its cooling system in a boost converter application 

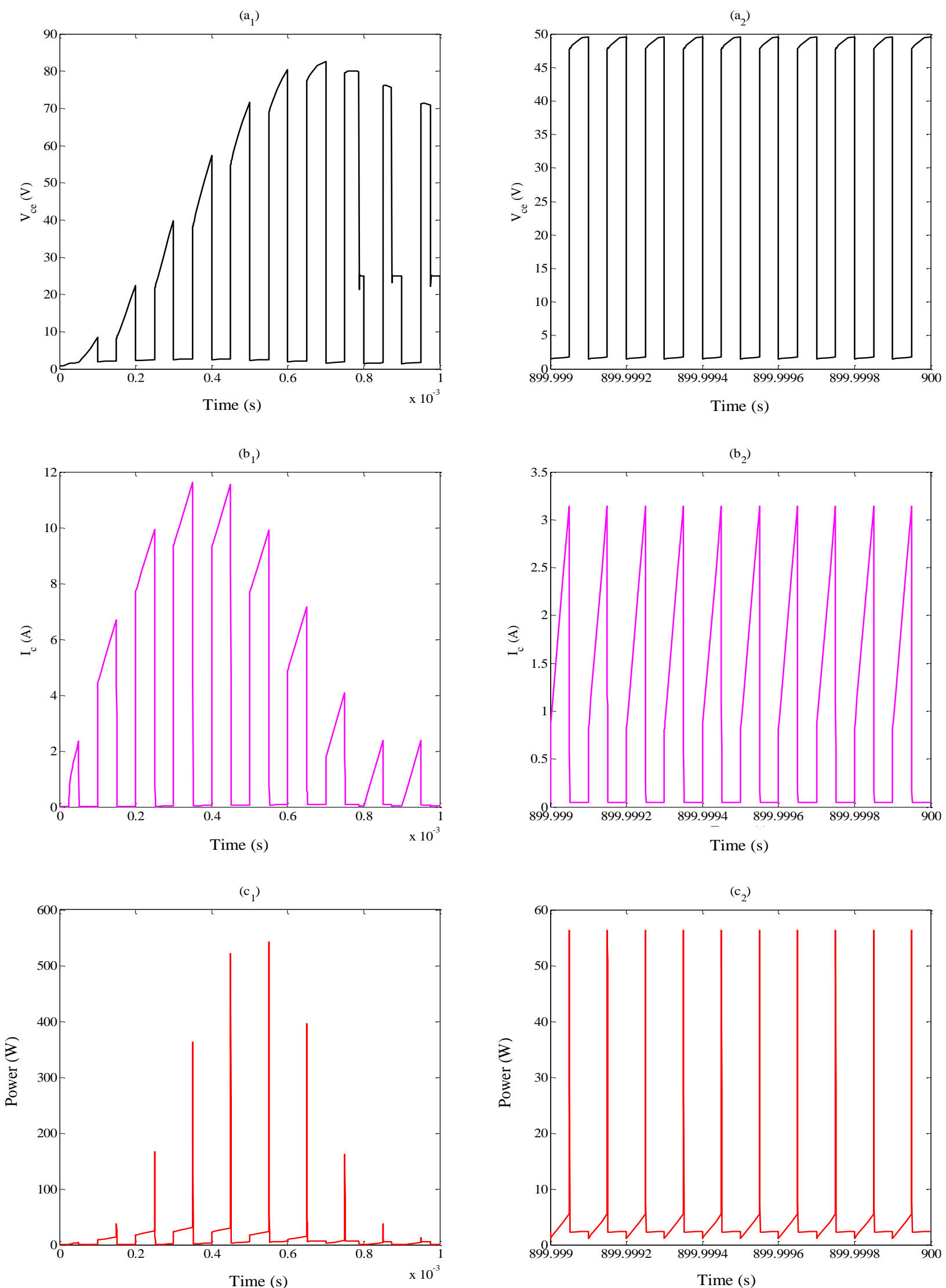

Fig. 14. Variations of the voltage, $V_{c e}$, the current, $I_{c}$, and the instantaneous power, $P$, for transient regime ((a1), (b1), and (c1)) and steady-state periodic regime ((a2), (b2), and (c2)) (D=0.5, $f=10 \mathrm{kHz})$ 


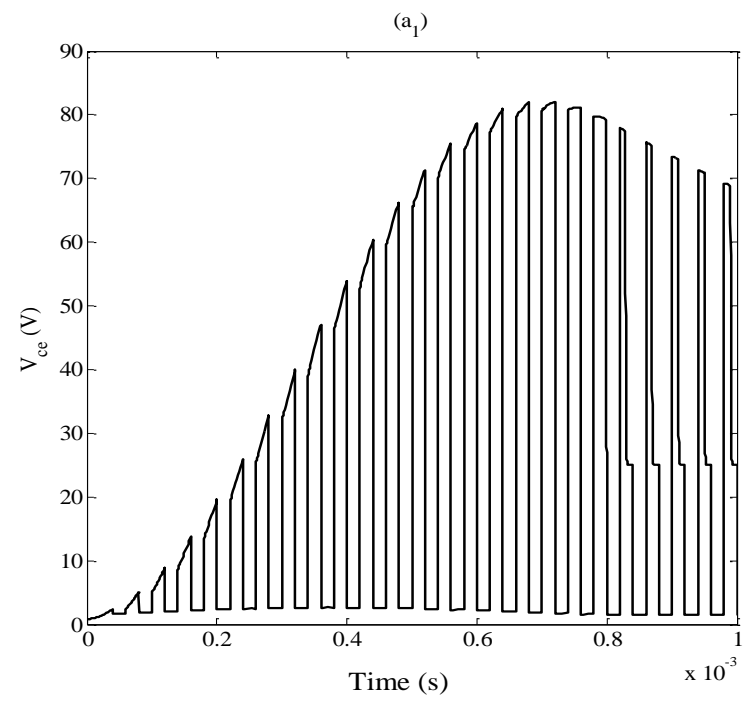

$\left(b_{1}\right)$

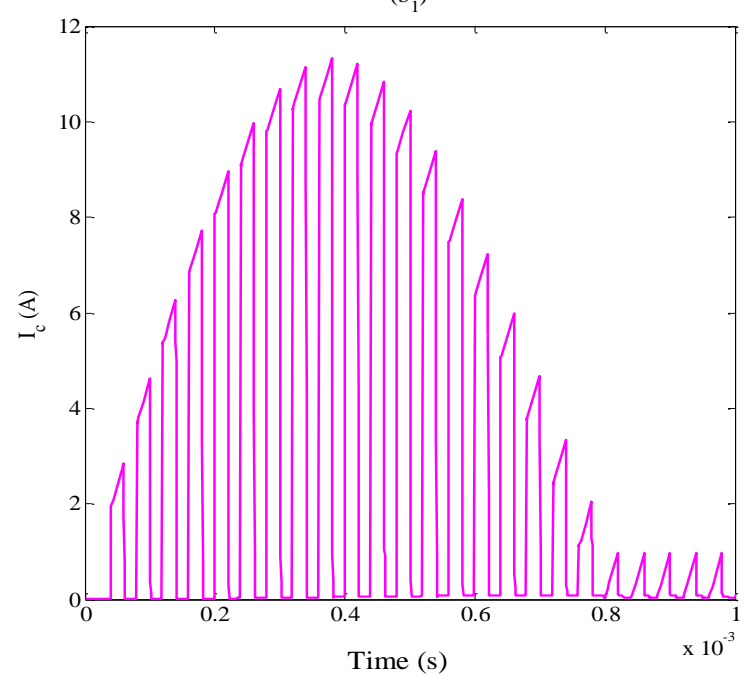

$\left(c_{1}\right)$

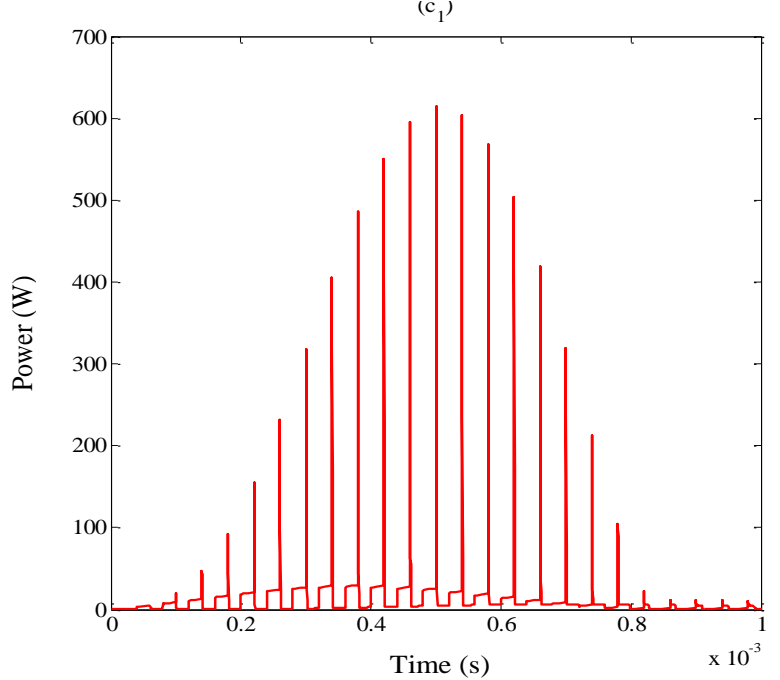

$\left(\mathrm{a}_{2}\right)$

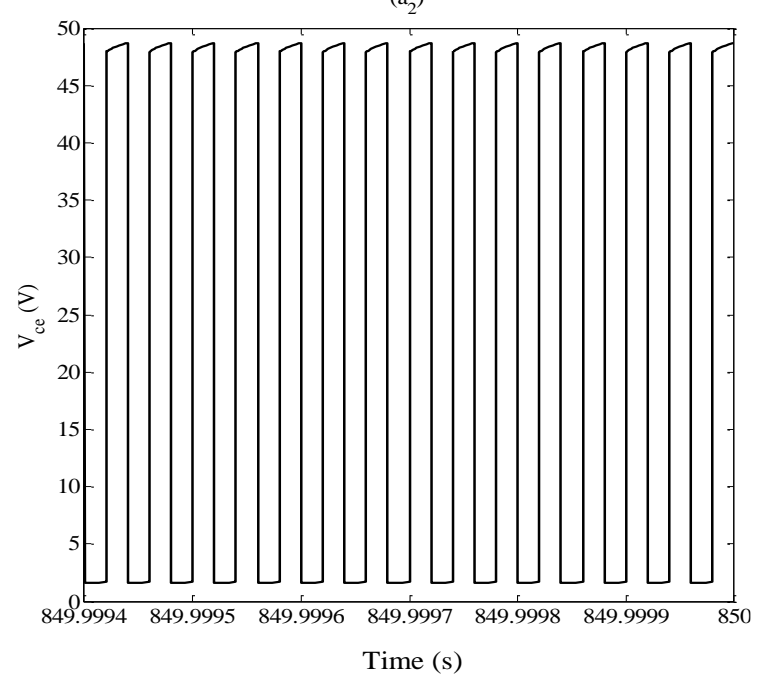

$\left(b_{2}\right)$

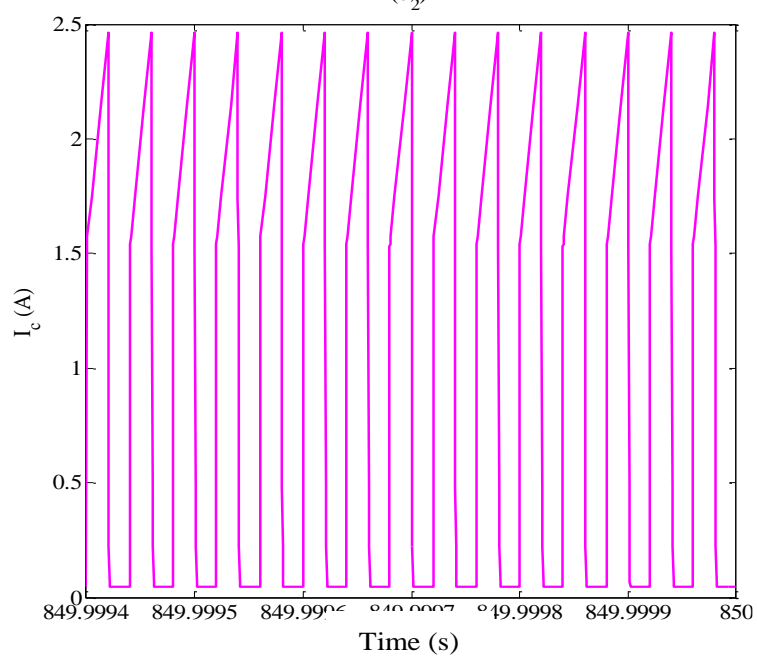

$\left(c_{2}\right)$

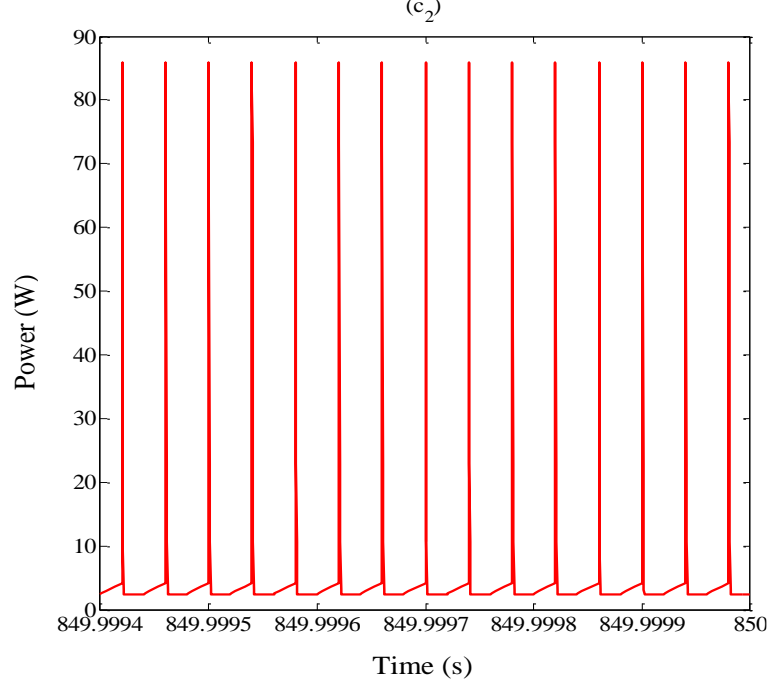

Fig. 15. Variations of the voltage, $V_{c e}$, the current, $I c$, and the instantaneous power, $P$, for transient regime ((a1), (b1), and (c1)) and steady-state periodic regime ((a2), (b2), and (c2)) (D=0.5, $f=25 \mathrm{kHz})$ 
$\left(a_{1}\right)$

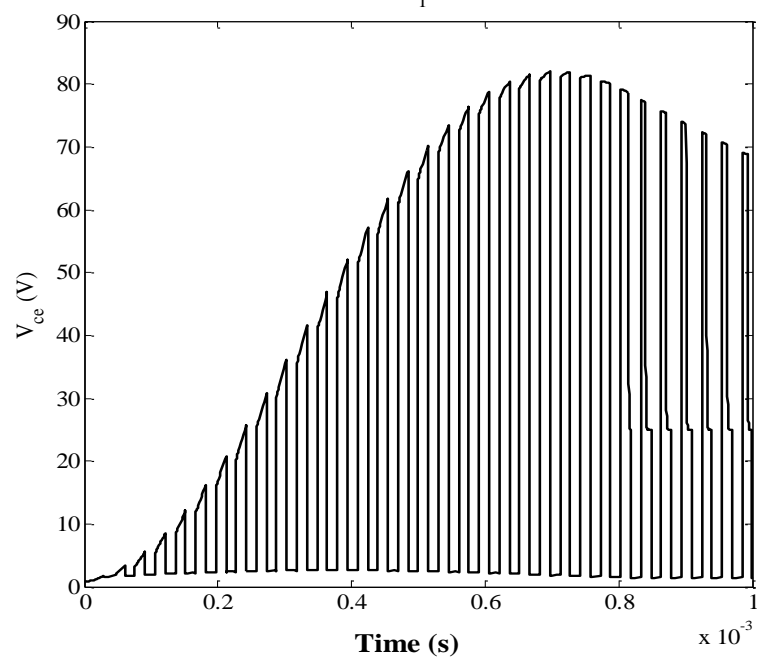

$\left(b_{1}\right)$

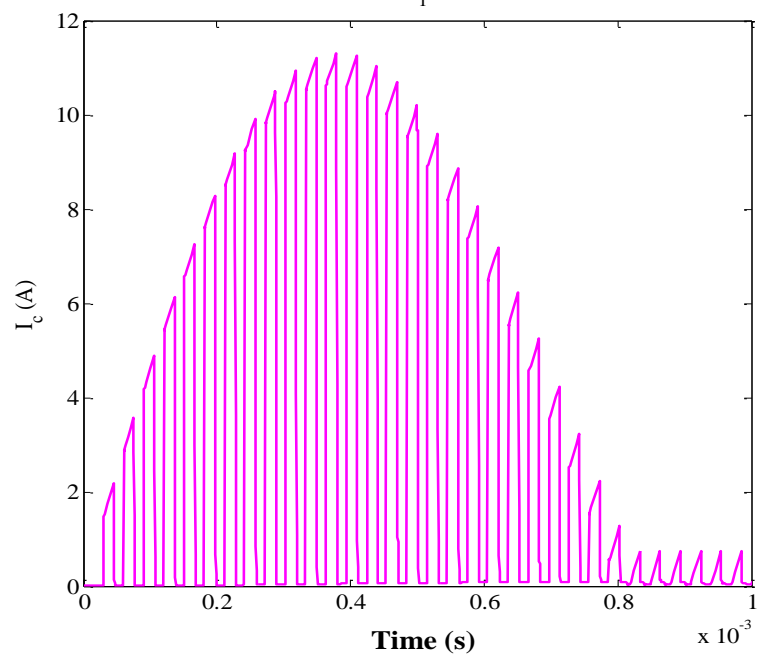

$\left(c_{1}\right)$

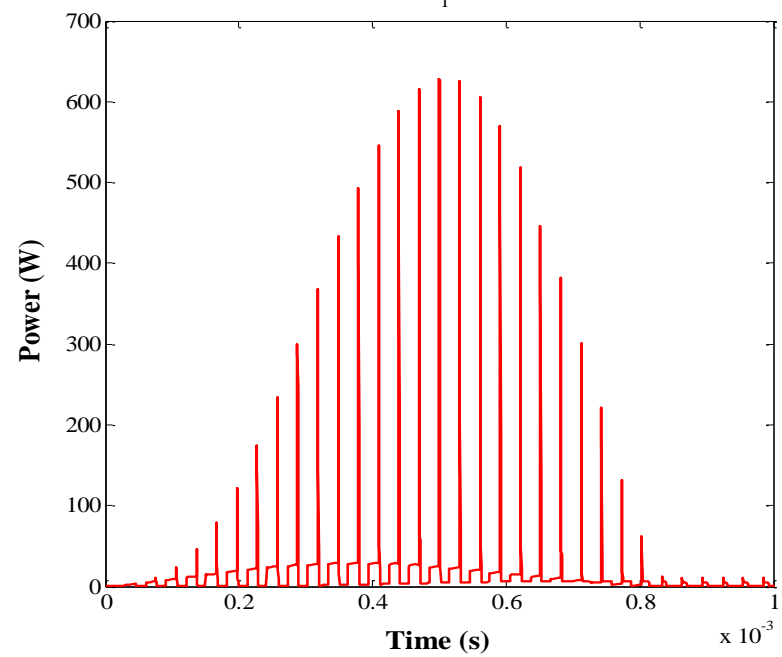

$\left(\mathrm{a}_{2}\right)$

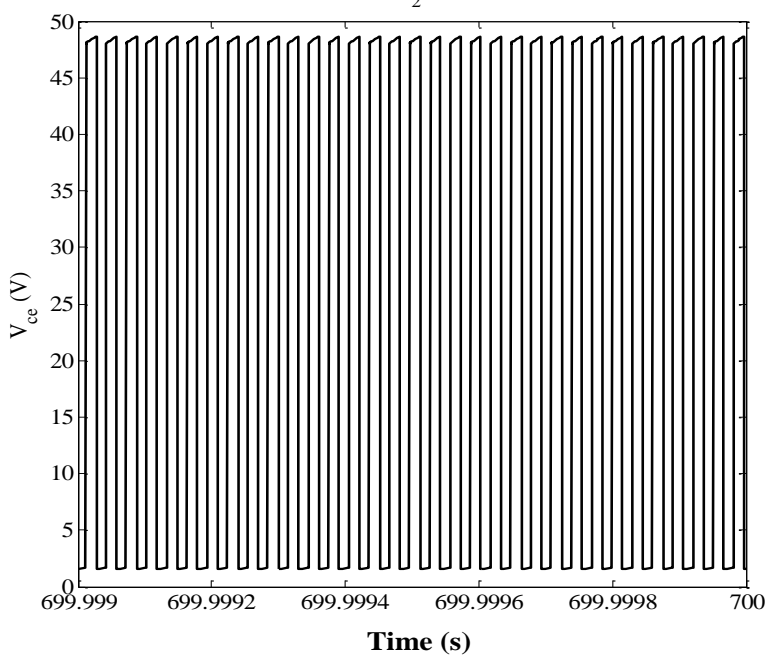

$\left(b_{2}\right)$

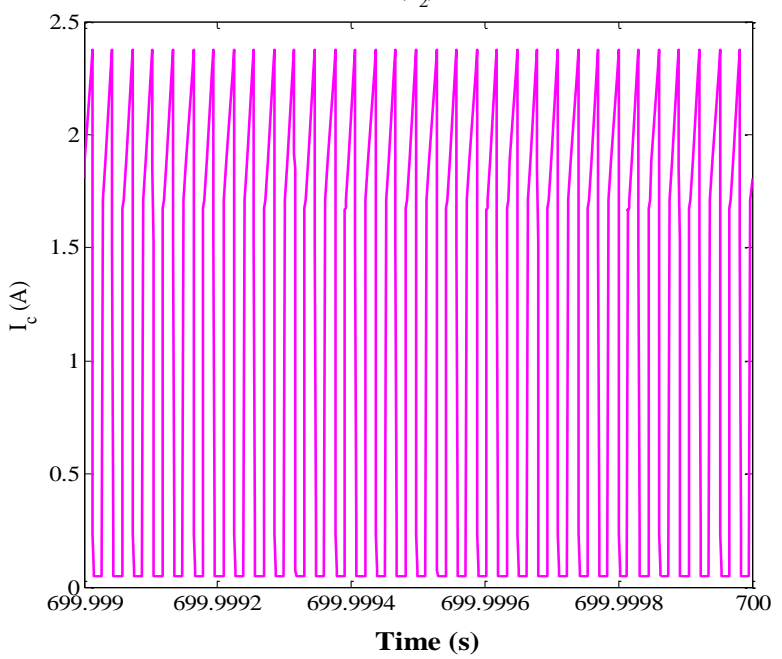

$\left(\mathrm{c}_{2}\right)$

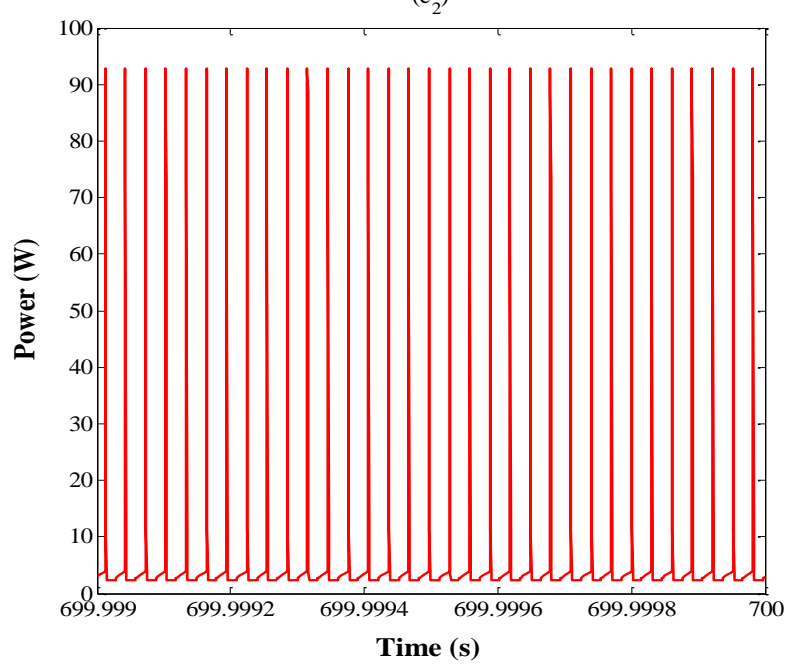

Fig. 16. Variations of the voltage, $V_{c e}$, the current, $I c$, and the instantaneous power, $P$, for transient regime ((a1), (b1), and (c1)) and steady-state periodic regime ((a2), (b2), and (c2)) (D=0.5, $f=33 \mathrm{kHz})$ 
The waveforms for the current, $I_{c}$, the tension, $V_{c e}$, and the instantaneous power, $P(t)$ are illustrated in transient and steady-state periodic regimes for a duty ratio, $D=0.5$, and commutation frequencies $f=10 \mathrm{kHz}, f=25 \mathrm{kHz}$, and $f=33 \mathrm{kHz}$, respectively. In the transient regime, the collectoremitter voltage increases and reaches up to $80 \mathrm{~V}$ for all commutation frequencies (Figure 14(a1), 15(a1), and 16(a1)). Then, it decreases to stabilize at nearly $50 \mathrm{~V}$ in the steady periodic regime (Figure 14(a2), 15(a2), and 16(a2)).

The collector current also increases at the beginning of the transient regime and reaches up to nearly $12 \mathrm{~A}$ for $\mathrm{f}=10 \mathrm{kHz}$ (Figure 14(b1)), $11.5 \mathrm{~A}$ for $\mathrm{f}=25 \mathrm{kHz}$ (Figure 15(b1)), and $11 \mathrm{~A}$ for $\mathrm{f}=33 \mathrm{kHz}$ (Figure 16(b1)). Then, it decreases to stabilize at $I_{c}=3.1 \mathrm{~A}$ for $f=10 \mathrm{kHz}$ (Figure 14(b2)), $\mathrm{I}_{\mathrm{c}}=2.5 \mathrm{~A}$ for $f=25 \mathrm{kHz}$ (Figure 15(b2)), and $I_{c}=2.4$ A for $f=33 \mathrm{kHz}$ (Figure 16(b2)).

The variations of the instantaneous electrical power that is calculated by Eq. (7) show that it reaches a maximum value of nearly $550 \mathrm{~W}$ for $f=10 \mathrm{kHz}$ (Figure 14(c1)), $600 \mathrm{~W}$ for $f=25 \mathrm{kHz}$ (Figure $15(c 1)$ ), and $640 \mathrm{~W}$ for $f=33 \mathrm{kHz}$ (Figure 16(c1)), which indicates that the electrical power increases with the commutation frequency. Then, the instantaneous electrical power decreases and stabilizes at values of nearly $58 \mathrm{~W}$ for $f=10 \mathrm{kHz}, 85 \mathrm{~W}$ for $f=25 \mathrm{kHz}$, and $92 \mathrm{~W}$ for $f=33 \mathrm{kHz}$ in the steady periodic regime (Figure 14(c2), 15(c2), and 16(c2)).

In the transient regime, the instantaneous electrical power is greater than the maximum heat power that can be dissipated by the heat pipe cooling system. However, since the commutation frequency is high, this hardly affects the junction temperature which increases from the heat sink temperature $\mathrm{T}_{\mathrm{hs}}=35^{\circ} \mathrm{C}$ to nearly $35.08{ }^{\circ} \mathrm{C}$, for $\mathrm{f}=10 \mathrm{kHz}$ (Figure $17(\mathrm{a})$ ) and to nearly $35.12{ }^{\circ} \mathrm{C}$ for $\mathrm{f}=$ $25 \mathrm{kHz}$ and $\mathrm{f}=33 \mathrm{kHz}$ (Figure $17(\mathrm{~b})$ and $17(\mathrm{c})$ ).

In the steady-state periodic regime, the junction temperature oscillates around an average value with a very low amplitude. Hence, the junction temperatures are nearly $35.9^{\circ} \mathrm{C}, 37.2{ }^{\circ} \mathrm{C}$, and $37.5^{\circ} \mathrm{C}$ for $f=10 \mathrm{kHz}, f=25 \mathrm{kHz}$, and $\mathrm{f}=33 \mathrm{kHz}$, respectively. Hence, the junction temperature of the IGBT is $0.1{ }^{\circ} \mathrm{C}, 2.2^{\circ} \mathrm{C}$, and $2.5^{\circ} \mathrm{C}$ higher than the heat sink temperature $\left(T_{h s}=35^{\circ} \mathrm{C}\right)$ for $f=10 \mathrm{kHz}, \mathrm{f}=25 \mathrm{kHz}$, and $f=33 \mathrm{kHz}$, respectively. This shows the effectiveness of the heat pipe cooling system, which provides nearly isothermal operation conditions of the IGBT. 

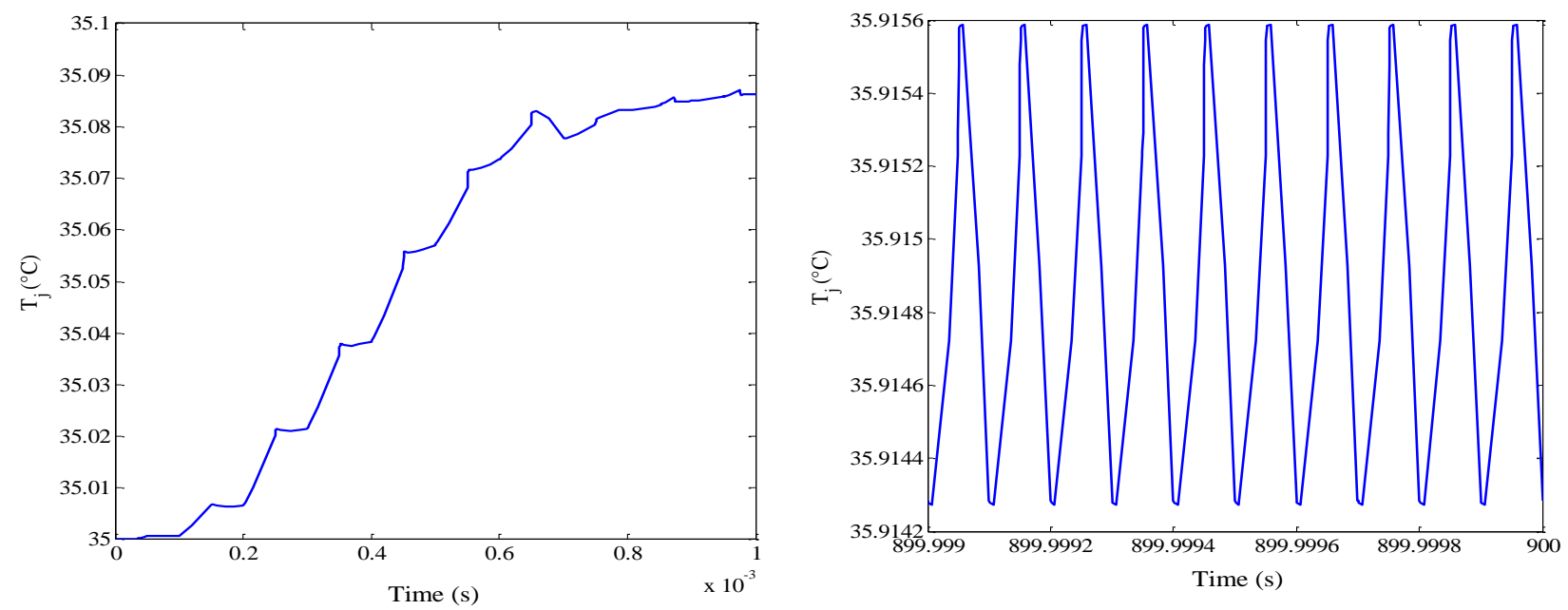

(a) $\mathrm{D}=0.5, \mathrm{f}=10 \mathrm{kHz}$
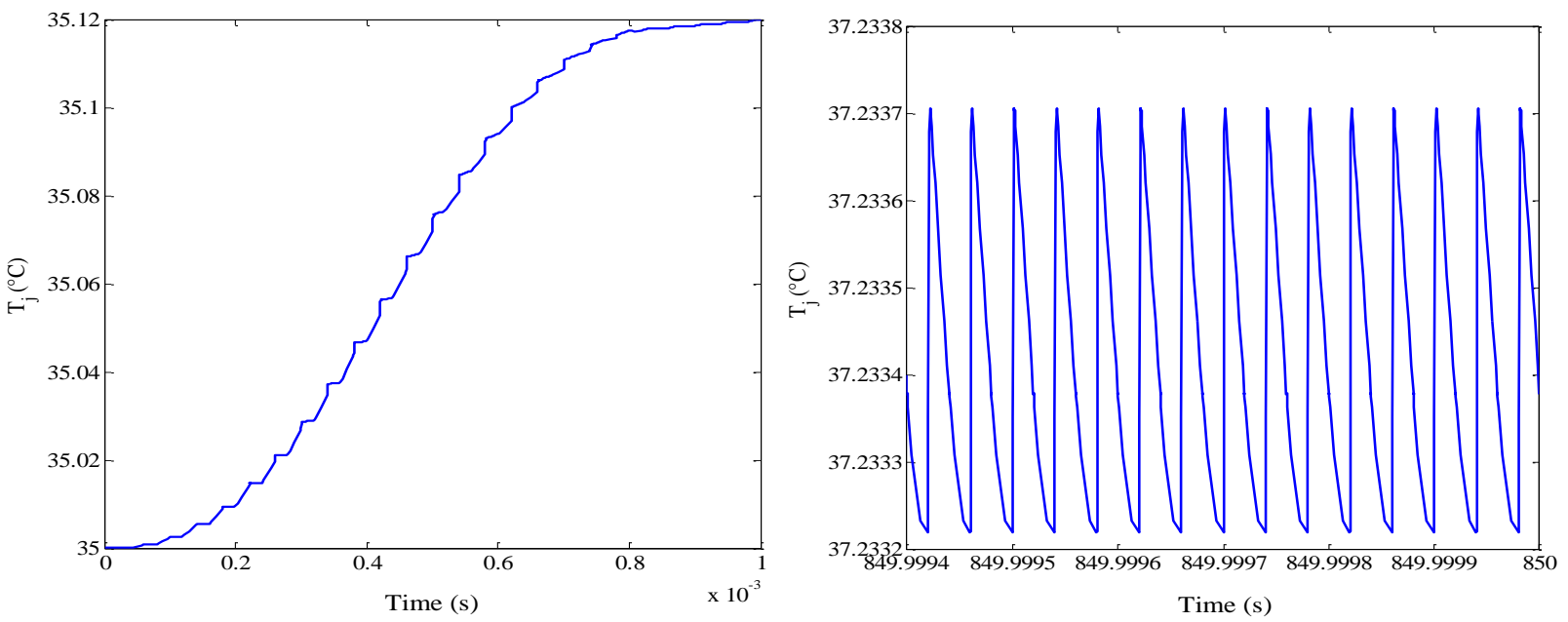

(b) $\mathrm{D}=0.5, \mathrm{f}=25 \mathrm{kHz}$
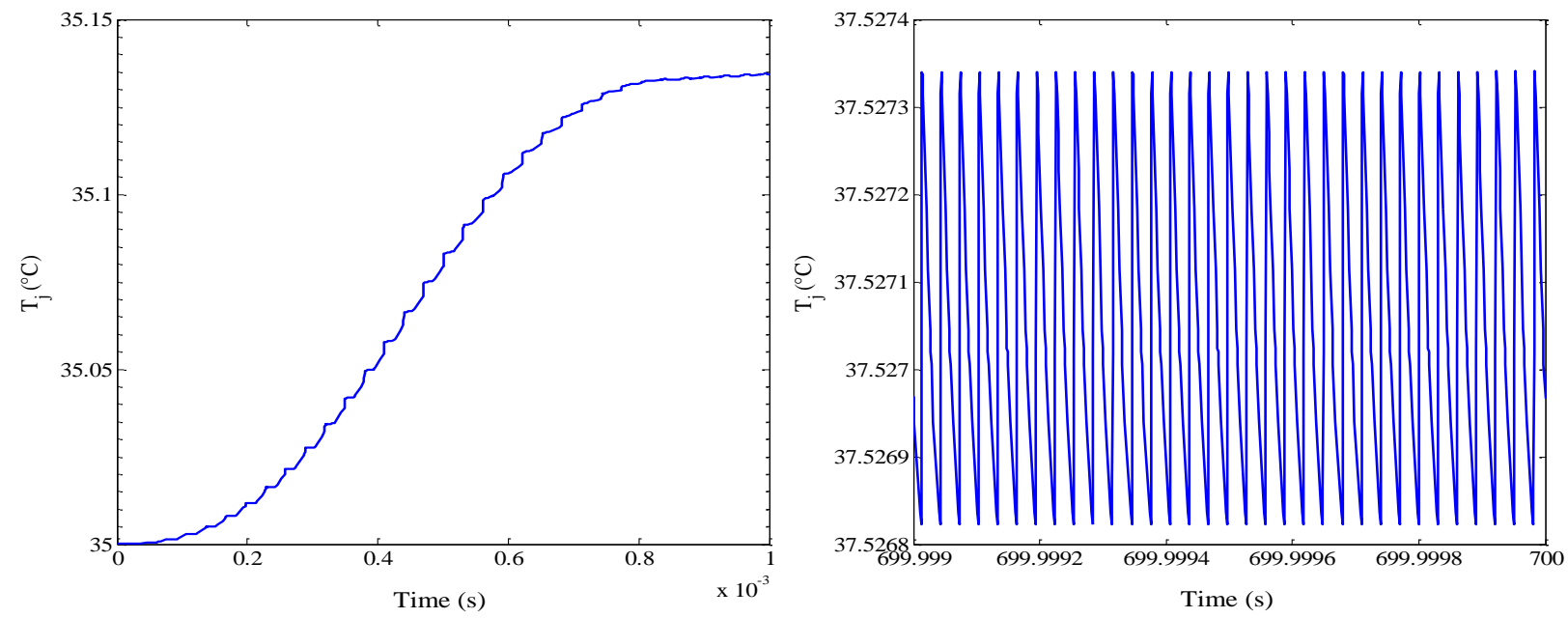

(c) $\mathrm{D}=0.5, \mathrm{f}=33 \mathrm{kHz}$

Fig. 17. Variations of the junction temperature for different commutation frequencies in the transient and steady-state periodic regimes 


\section{Conclusions}

In this work, we analyzed the thermal management of an IGBT cooled by a heat pipe system. Firstly, a thermal model of the heat pipe cooling system is proposed. It is based on thermal RC cells. The thermal resistances of the network RC circuit are determined from the experimental results and the thermal capacitances are calculated theoretically based on the hydrodynamic and material characteristics of the heat pipe cooling system as well as its material characteristics. The model of the water-cooled heat pipe system was validated by experiments for various operating heat input powers and heat sink temperatures. Secondly, a thermal model for predicting the IGBT junction temperature based on a thermal RC network is developed. This model is elaborated based on the thermal impedance that is determined by the manufacturer tests. Thirdly, an electrical model is developed based on the one which is already implemented in the SimPowerSystems library of MATLAB and modified to consider the effect of the junction temperature in the expressions of the on-state resistance and the threshold voltage that are issued from experiments. Finally, an electrothermal model for an IGBT, which is used in a boost converter application, was developed.

The numerical results show that the heat input power dissipated by the IGBT depends on the commutation frequency. In the initial stage of the IGBT transient operation, the dissipated power is high and reaches up to $640 \mathrm{~W}$ for a commutation frequency of $33 \mathrm{kHz}$. This power is higher than the maximum heat transport capacity of the cooling system which is equal to $125 \mathrm{~W}$ for $\mathrm{T}_{\mathrm{hs}}=35^{\circ} \mathrm{C}$, however, it hardly affects the junction temperature since the duration of the initial stage of the transient operation is very short when compared to the thermal constant time of the cooling system. In a steady-periodic operation regime, the dissipated power of the IGBT, which does not exceed 100 $\mathrm{W}$ for high commutation frequencies, is lower than the maximum heat transport capacity of the cooling system, and it is demonstrated that the junction temperature is $2.5^{\circ} \mathrm{C}$ higher than the heat sink temperature which enables a safe IGBT operation.

\section{References}

[1] Fikri, Bintang, Nandy Putra, Adi Winarta, Nasruddin A. Abdullah, and Bambang Ariantara. "Experimental investigation of modified direct evaporative cooler using heat pipe." Journal of Advanced Research in Fluid Mechanics and Thermal Sciences 55, no. 2 (2019): 209-217.

[2] Abdullahi, Bala, Ahmed Elsayed, Raya Al-Dadah, Sa'ad Mahmoud, Abdel Fateh Mahrous, Nura Mu'az Muhammad, and Saidu Bello Abbakar. "Experimental and numerical investigation of thermosyphon heat pipe performance at various inclination angles." Journal of Advanced Research in Fluid Mechanics and Thermal Sciences 44, no. 1 (2018): 85-98.

[3] Baheta, Aklilu Tesfamichael, Ahmed N. Oumer, and Sintayehu M. Hailegiorgis. "Analysing the thermal performance of heat pipe using copper nanofluids." Journal of Advanced Research in Fluid Mechanics and Thermal Sciences 45, no. 1 (2018): 149-155.

[4] Rogers, Susan A. "Annual Progress Report for the Advanced Power Electronics and Electric Machinery Program." 2007 Annual Progress Report, Vehicle Technologies Program, US DOE (2007).

[5] Bazzo, João Paulo, Tiago Lukasievicz, Marcio Vogt, Valmir de Oliveira, Hypolito José Kalinowski, and Jean Carlos Cardozo da Silva. "Thermal characteristics analysis of an IGBT using a fiber Bragg grating." Optics and Lasers in Engineering 50, no. 2 (2012): 99-103. https://doi.org/10.1016/i.optlaseng.2011.08.009

[6] Avenas, Yvan, and Laurent Dupont. "Evaluation of IGBT thermo-sensitive electrical parameters under different dissipation conditions-Comparison with infrared measurements." Microelectronics Reliability 52, no. 11 (2012): 2617-2626. https://doi.org/10.1016/i.microrel.2012.03.032

[7] Avenas, Yvan, Laurent Dupont, and Zoubir Khatir. "Temperature measurement of power semiconductor devices by thermo-sensitive electrical parameters-A review." IEEE transactions on power electronics 27, no. 6 (2011): 30813092. https://doi.org/10.1109/TPEL.2011.2178433

[8] Lee, Tien-Yu. "Design optimization of an integrated liquid-cooled IGBT power module using CFD technique." IEEE Transactions on Components and Packaging Technologies 23, no. 1 (2000): 55-60. https://doi.org/10.1109/6144.833042 
[9] Hefner, Allen R. "A dynamic electro-thermal model for the IGBT." IEEE Transactions on Industry Applications 30, no. 2 (1994): 394-405. https://doi.org/10.1109/28.287517

[10] Hsu, J-T., and Khai DT Ngo. "Behavioral modeling of the IGBT using the Hammerstein configuration." IEEE transactions on Power Electronics 11, no. 6 (1996): 746-754. https://doi.org/10.1109/63.542037

[11] Ammous, Anis, Sami Ghedira, Bruno Allard, Hervé Morel, and Denise Renault. "Choosing a thermal model for electrothermal simulation of power semiconductor devices." IEEE Transactions on Power Electronics 14, no. 2 (1999): 300-307. https://doi.org/10.1109/63.750183

[12] Ammous, Anis, Kaiçar Ammous, Hervé Morel, Bruno Allard, Dominique Bergogne, Fayçal Sellami, and Jean Pierre Chante. "Electrothermal modeling of IGBTs: Application to short-circuit conditions." IEEE Transactions on Power Electronics 15, no. 4 (2000): 778-790. https://doi.org/10.1109/63.849049

[13] Luo, Zhaohui, Hyungkeun Ahn, and M. A. E. Nokali. "A thermal model for insulated gate bipolar transistor module." IEEE Transactions on Power Electronics 19, no. $4 \quad$ (2004): $902-907$. https://doi.org/10.1109/TPEL.2004.830089

[14] Kojima, Takashi, Yuji Nishibe, Yasushi Yamada, Takashi Ueta, Kaoru Torii, Shoichi Sasaki, and Kimimori Hamada. "Novel electro-thermal coupling simulation technique for dynamic analysis of HV (hybrid vehicle) inverter." In 2006 37th IEEE Power Electronics Specialists Conference, pp. 1-5. IEEE, 2006.

[15] Ciappa, Mauro, Wolfgang Fichtner, T. Kojima, Y. Yamada, and Y. Nishibe. "Extraction of accurate thermal compact models for fast electro-thermal simulation of IGBT modules in hybrid electric vehicles." Microelectronics Reliability 45, no. 9-11 (2005): 1694-1699. https://doi.org/10.1016/i.microrel.2005.07.083

[16] Du, Bin, Jerry L. Hudgins, Enrico Santi, Angus T. Bryant, Patrick R. Palmer, and Homer Alan Mantooth. "Transient electrothermal simulation of power semiconductor devices." IEEE Transactions on power electronics 25, no. 1 (2009): 237-248. https://doi.org/10.1109/TPEL.2009.2029105

[17] Hefner Jr, Allen R., and David L. Blackburn. "An analytical model for the steady-state and transient characteristics of the power insulated-gate bipolar transistor." Solid-State Electronics 31, no. 10 (1988): 1513-1532. https://doi.org/10.1016/0038-1101(88)90025-1

[18] Kraus, R., P. Turkes, and J. Sigg. "Physics-based models of power semiconductor devices for the circuit simulator SPICE." In PESC 98 Record. 29th Annual IEEE Power Electronics Specialists Conference (Cat. No. 98CH36196), vol. 2, pp. 1726-1731. IEEE, 1998.

[19] Tichenor, Jerry L., Scott D. Sudhoff, and James L. Drewniak. "Behavioral IGBT modeling for predicting high frequency effects in motor drives." IEEE Transactions on Power Electronics 15, no. 2 (2000): 354-360. https://doi.org/10.1109/63.838108

[20] Oh, Hyeong-Seok, and Mahmoud El Nokali. "A new IGBT behavioral model." Solid-State Electronics 45, no. 12 (2001): 2069-2075. https://doi.org/10.1016/S0038-1101(01)00149-6

[21] Azar, R., F. Udrea, M. De Silva, G. Amaratunga, W. T. Ng, F. Dawson, W. Findlay, and P. Waind. "Advanced SPICE modeling of large power IGBT modules." In Conference Record of the 2002 IEEE Industry Applications Conference. 37th IAS Annual Meeting (Cat. No. 02CH37344), vol. 4, pp. 2433-2436. IEEE, 2002.

[22] Asparuhova, Katya, and Tsvetana Grigorova. "IGBT high accuracy behavioral macromodel." In 2008 26th International Conference on Microelectronics, pp. 185-188. IEEE, 2008. https://doi.org/10.1109/ICMEL.2008.4559254

[23] Frisina, F., C. Leonardi, Angelo Raciti, and Salvatore Torrisi. "Physics based model of punch through IGBTs simulated by PSpice." In COM. P. EL. 98. Record 6th Workshop on Computer in Power Electronics (Cat. No. 98TH8358), pp. 2735. IEEE, 1998.

[24] Driss, Améni, Samah Maalej, and Mohamed Chaker Zaghdoudi. "Experimentation and modeling of the steady-state and transient thermal performances of a helicoidally grooved cylindrical heat pipe." Microelectronics Reliability 62 (2016): 102-112. https://doi.org/10.1016/i.microrel.2016.03.022

[25] Driss, A., M. B. H. Sassi, S. Maalej, and M. C. Zaghdoudi. "Transient thermal performance modeling and experimentation of heat pipes for high power electronics cooling." International Review on Modeling and Simulations (IREMOS) 5, no. 6 (2012): 2473-2483.

[26] Semitrans. "Semitrans IGBT module (SKM75GB123D)." (2009).

[27] Gerstenmaier, York C., Walter Kiffe, and Gerhard Wachutka. "Combination of thermal subsystems modeled by rapid circuit transformation." In 2007 13th International Workshop on Thermal Investigation of ICs and Systems (THERMINIC), pp. 115-120. IEEE, 2007. https://doi.org/10.1109/THERMINIC.2007.4451758

[28] Gerstenmaier, Y. C., W. Kiffe, and G. Wachutka. "Combination of thermal subsystems by use of rapid circuit transformation and extended two-port theory." Microelectronics Journal 40, no. 1 (2009): 26-34. https://doi.org/10.1016/i.mejo.2008.09.002

[29] Ayadi, M., M. A. Fakhfakh, M. Ghariani, and R. Neji. "Electro-thermal simulation of a three phase inverter with cooling system." Journal of Modelling and Simulation of Systems 1, no. 3 (2010): 163-170. 